\title{
El incómodo lugar de la educación pública en el sistema educacional chileno. Análisis sociohistórico del proceso de decaimiento de la educación pública chilena
}

\author{
The uncomfortable place of the education public \\ in the Chilean system educational \\ Socio-historical analysis of the process of decay \\ of the Chilean public education
}

Pablo Barrientos $S .{ }^{*}$ y Tomás Ilabaca $T .{ }^{* *}$

\section{RESUMEN}

El presente artículo es un análisis sociohistórico de la relación entre la educación pública y la educación privada subvencionada en Chile, con énfasis en las últimas tres décadas y en las consecuencias de las políticas implantadas en el último periodo para la educación pública. Dicha relación se ha configurado en dos grandes etapas de la historia chilena: 1) la historia educativa previa a la dictadura militar, donde la educación pública poseía una alta valoración social y tenía el rol de educar a la mayor parte de la población (Estado docente), mientras que la educación particular poseía una menor relevancia, y 2) posterior a la reforma realizada por la dictadura (1973-1989) donde se pone a competir bajo las reglas del mercado tanto a la educación pública como a la privada, siendo esta última la gran favorecida. Las consecuencias son la segregación, la desigualdad de oportunidades y la búsqueda de distinción que vienen a agrandar las desigualdades sociales del país. Por último, se revisarán las llamadas políticas de focalización y las políticas que engloba la Reforma educativa del segundo gobierno de Michelle Bachelet.

Palabras clave: Sistema educacional chileno, educación pública, educación particular subvencionada, segregación escolar, desigualdad educativa

\section{ABSTRACT}

This article is a socio-historical analysis of the relationship between public education and private subsidized education in Chile, emphasizing the last three decades and the consequences for public education of these policies implemented in the last period. This relationship is configured in two stages of the Chilean educational history: 1) the educational history before to the military dictatorship, where public education had a high social value and had the role of educating the majority of the population ("Teacher State"), while private education was less significant, and 2) post-reform by the dictatorship (1973-1989) where public and private education have to compete under market rules, being great favored the private sector. The consequences are segregation, unequal opportunities and the pursuit of distinction who come to enlarge the social inequalities. Finally, we review the "targeting policies" and the educational reform during the second government of Michelle Bachelet.

Key words: Chilean educational system, public education, private subsidized education, school segregation, educational inequality

"Academia de Pedagogía en Filosofía de la Facultad de Filosofía y Humanidades en la Universidad Alberto Hurtado; pablofj.barrientos@gmail.com.

" Centro de Estudios del Desarrollo (CED). Universidad Alberto Hurtado; tomas.ilabaca@ced.cl. 


\section{INTRODUCCIÓN}

El presente artículo busca realizar un análisis sociohistórico del proceso de deterioro y decaimiento de la educación pública en Chile. En el contexto sociopolítico actual se comienzan a cuestionar y a cambiar las bases ideológicas y estructuras del sistema educativo implantado en plena dictadura (Mayol y Azocar, 2011) por medio de movilizaciones y reformas, y se torna imprescindible observar el desarrollo de las políticas educativas en las últimas décadas, a fin de comprender los cambios que se están proponiendo para el sistema educacional chileno. En este, siempre han cohabitado la educación pública y la privada, con una relevancia histórica mayor (tanto desde la sociedad civil como desde la política pública) la primera por sobre la segunda, pero es a partir de las modificaciones llevadas a cabo por la dictadura militar que se puso - por medio de una profunda reforma ideológica (sin sustento empírico científico) - a la educación pública en un escenario de competitividad, regulación mercantil y menoscabo que la ha llevado a poseer un poco más de $36.4 \%$ de la matrícula nacional (Centro de Estudios MINEDUC, 2015).

CUADRO 1. Distribución de la matrícula según tipo de dependencia, 2015

\begin{tabular}{|l|l|c|c|}
\hline \multicolumn{2}{|c|}{ Dependencia Administrativa } & N & $\%$ \\
\hline \multirow{2}{*}{ Municipal } & 1290770 & 36.40 \\
\cline { 2 - 4 } & Particular Subvencionado & 1935222 & 54.50 \\
\cline { 2 - 4 } & Particular Pagado & 276892 & 7.80 \\
\hline Corporación de Administración Delegada & 45852 & 1.30 \\
\cline { 2 - 4 } & Total & 3548736 & 100 \\
\hline
\end{tabular}

Fuente: Elaboración propia a partir de Base de Datos Matrícula Oficial. Año 2015, Centro de Estudios Mineduc, 2015.

Las consecuencias de esta realidad es que el Estado chileno ha tenido que llevar a cabo reformas estructurales para "emparejar la cancha" de las reglas del juego, es decir, el marco regulatorio del sistema educativo chileno. A nuestro juicio, estas reformas, por sí solas, no solucionarán el problema de la educación pú- 
blica nacional, pues no apuntan hacia el problema de fondo del sistema educativo (su mercantilización y financiamiento), por lo que, si no se realizan verdaderas reformas que apunten hacia una valoración y mejora de la educación pública, terminaremos con un Estado que tendrá que realizar políticas educativas orientadas hacia el sector particular subvencionado.

Por ende, y a través de un análisis sociológico histórico, pretendemos entender los procesos socioeducativos y los resultados que estos han generado en el sistema educativo chileno, específicamente en la educación pública, con el fin de explicar la actual posición que ocupa la educación pública en la valoración social y educativa. Para realizar este análisis, tomaremos las políticas educativas que van desde el periodo de la dictadura militar hasta el actual gobierno de Michelle Bachelet, a fin de entender la justificación de los cambios propuestos actualmente y evaluar sus potencialidades.

\section{ANTECEDENTES HISTÓRICOS DE LA EDUCACIÓN PÚBLICA CHILENA}

Ya que el Estado no puede con sus propios recursos proveer en toda su extensión a las exigencias de la enseñanza, provechoso es que proporcione estímulos y facilidades a los establecimientos de educación dirigidos por particulares.

Discurso de Federico Errázuriz (en Serrano, 1993: 227)

Históricamente, la educación pública en Chile fue de gran importancia para el desarrollo social, político e intelectual del país. Los principales esfuerzos en materia escolar por parte del Estado chileno fueron orientados hacia la consolidación de un sistema educativo público-estatal, el cual se desarrolló desde la primera mitad del siglo XIX hasta la irrupción de la dictadura militar, en 1973. Ahora bien, hay que reconocer que el Estado no era el único oferente educativo para la sociedad: desde tiempos coloniales existían escuelas fundadas por sacerdotes misioneros y congregaciones.

Como primer antecedente histórico, diremos que la corona española no tenía como prioridad la educación de sus colonias; por esta razón, las seis escuelas de Santiago hacia finales del siglo XVIII dependían de conventos. La matrícula total era 108 alum- 
nos (Egaña, 2000: 25), la mayor parte eran hijos de los criollos acomodados; sin embargo, existía una pequeña porción de alumnos pobres que estudiaban gratis.

Gracias al espíritu de Independencia, surgió la necesidad de educar al pueblo con la intención de "formar ciudadanos para una nueva República”. Por esta razón, en la Junta de Gobierno de 1813, a cargo de José Miguel Carrera, se dictó la "Disposición fundamental sobre la materia" que reglamentaba la educación primaria y destacaba la responsabilidad del Estado sobre esta actividad educativa" (ibid.).

Durante esta primera mitad del siglo XIX surge una preocupación por la educación del pueblo por parte de las élites dirigentes. Entre 1813 y 1830 se firmaron las primeras Constituciones de la República y se fundó el Instituto Nacional - "primer foco de luz de la nación”- para educar a la élite dirigente. Además, se probaron distintas iniciativas para educar al pueblo. La visión iluminista liberal, siguiendo a Egańa, vio en la educación un medio -tal vez, el único medio- para instaurar la nación chilena en la conciencia del pueblo.

En la década de 1840, el Estado encargó la tarea de reformar "la instrucción primaria" a un grupo de intelectuales, entre los que se encontraban Domingo Sarmiento, Andrés Bello, los hermanos Amunátegui y José Victorino Lastarria. El intelectual venezolano Andrés Bello funda la Universidad de Chile en 1843, y con ella se funda también la Escuela Normal de preceptores. Domingo Justino Sarmiento, intelectual argentino exiliado en Chile, será director de la Escuela Normal. En este contexto, Lastarria plantea una moción ante la cámara de diputados en agosto de 1843 que inspirará la primera ley general sobre educación de nuestro país. En dicha moción, se reitera la idea de la responsabilidad educativa del Estado, la cual se traducía en financiar y mantener escuelas gratuitas de instrucción primaria para atender a quienes no podían pagar por su educación.

Según los registros históricos, hacia 1843 existían ocho escuelas municipales, siete conventuales, tres parroquiales, y 60 particulares (Egaña, 2000). En 1856 se establece la Sociedad de Instrucción Primaria, la cual constituye un gran aporte a la educación popular por parte de los particulares. Bajo el gobierno 
de Manuel Bulnes se señalaba que, de 78 escuelas primarias, de las cuales 60 eran particulares, mientras que el resto pertenecía a municipios o eran propiedad de la Iglesia (Ossa, 2007). Todas estas funcionando con subvenciones estatales (claramente menores que las que recibían las escuelas estatales). Esto nos da cuenta de que, desde los inicios de la República de Chile, existe un sistema de provisión mixta en el que las familias podían escoger la escuela de sus hijos (Ossa, 2007; Serrano et al., 2012).

En los cambios realizados a la constitución de 1879 se ratifica el ideario de educación mixta con el dictamen de la nueva ley, en que se daba espacio para que particulares pudieran fundar colegios primarios y secundarios. Aun así, quien poseía el predominio en cuanto a diseño de políticas públicas educativas seguía siendo el Estado, y en particular, el sentido de este hacia una educación laica, haciendo obligatoria la examinación oficial Estatal de los egresados de colegios particulares religiosos (Serrano, 1993).

Luego de estas reformas, la siguiente más importante en la historia de la educación chilena es la Ley de Instrucción Primaria obligatoria, promulgada en 1920, que establece, justamente, la obligatoriedad de la educación primaria y la gratuidad de los establecimientos públicos estatales. Se impusieron obligaciones tanto en el funcionamiento como en las subvenciones, pero en ningún caso se prohibió la educación privada o confesional y menos los recursos dirigidos hacia esta, es decir, se mantenía el sistema mixto de provisión y, por lo tanto, la libertad de enseñanza. La cantidad de escuelas públicas aumentó con esta Ley (Egaña, 2000).

Ahora bien, a pesar de que en el sistema la educación pública tenía una fuerte presencia y valoración, el aparato escolar era poco inclusivo y se encontraba estratificado: los alumnos de las escuelas primarias de entonces, en su mayoría, eran de sectores populares debido a que los hijos de la élite social y económica eran educados en las casas (esto empezó a cambiar específicamente en 1920, cuando se dicta la Ley de Instrucción Primaria Obligatoria). La secundaria -liceos como el Instituto Nacionalsí estaba destinada a los hijos de las élites gobernantes debido a que era en estos establecimientos donde se formaba la clase gobernante y a la cual no accedían las clases populares. Es decir, junto a constatar el inicio de un sistema educativo de provisión 
mixta, también, en un segundo plano, observamos que se cumple el diagnóstico formulado por Pierre Bourdieu en su libro Razones prácticas, donde señala que:

El sistema escolar actúa como el demonio de Maxwell: a costa del gasto de energía necesaria para llevar a cabo la operación de selección, mantiene el orden preexistente, es decir, la separación entre los alumnos dotados de cantidades desiguales de capital cultural (Bourdieu, 2007: 34).

Los establecimientos estatales (o en algunos casos, municipales) siempre obtenían mayores recursos (subvenciones) que los establecimientos particulares (véase Cuadro 2). Estos últimos, previo a los primeros aportes vía subvención regulada por ley (1954), eran financiados por el Estado para otorgar educación en zonas aisladas o donde se estaban poblando regiones geográficas (en el sur de Chile, el Estado financió colegios privados, generalmente creados por los colonos alemanes). Un ejemplo de lo que señalamos es el siguiente cuadro:

CUADRO 2. Presupuesto y subvenciones a escuelas entre 1906 y 1920

\begin{tabular}{|c|c|c|c|c|}
\hline \multicolumn{5}{|c|}{ Valores nominales } \\
\hline Año & $\begin{array}{c}\text { Presupuesto total } \\
\text { de la Nación }\end{array}$ & $\begin{array}{c}\text { Presupuesto de } \\
\text { instrucción pública }\end{array}$ & $\begin{array}{c}\text { Presupuesto } \\
\text { de subvenciones }\end{array}$ & $\begin{array}{c}\text { Número de subvenciones } \\
\text { yasignaciones varias a } \\
\text { establecimientos particulares }\end{array}$ \\
\hline 1906 & 123863254 & 17645008 & 744200 & 243 \\
\hline 1907 & 134830532 & 16086512 & 829600 & 270 \\
\hline 1908 & 157715666 & 21487715 & 1403700 & 322 \\
\hline 1909 & 175084403 & 24508168 & 1917700 & 388 \\
\hline 1910 & 197230075 & 26344133 & 1513100 & 357 \\
\hline 1911 & 241784383 & 32184104 & 1604260 & 483 \\
\hline 1912 & 280894117 & 43240682 & 1914020 & 377 \\
\hline 1913 & 257912469 & 37770312 & 1412150 & 361 \\
\hline 1914 & 252626972 & 38993906 & 1272550 & 363 \\
\hline 1915 & 184091845 & 32802073 & 895350 & 373 \\
\hline 1916 & 208021829 & 32875213 & 886450 & 381 \\
\hline 1917 & 193432264 & 33648997 & 939950 & 389 \\
\hline 1918 & 206994237 & 37073214 & 849020 & 405 \\
\hline 1919 & 234935607 & 44425530 & 947740 & 973750 \\
\hline 1920 & 260850397 & 45006960 & & 406 \\
\hline
\end{tabular}

Fuente: Ossa, 2007. 
La siguiente gran reforma educativa se llevó a cabo en 1965, por el presidente Eduardo Frei Montalva. En ella se hicieron cambios curriculares y de estructura del sistema educativo, pasando de dos ciclos escolares de seis años cada uno (primaria y secundaria) a uno de ocho años (educación básica) y otro de cuatro años (educación media), con el propósito de aumentar la matrícula y, por ende, la cobertura escolar; en conjunto con eso, la mayor cantidad de años de educación obligatoria (pasó de seis a ocho) tiene un claro impacto en las clases populares que poseían un menor capital cultural. Con dicha reforma, la cobertura aumentó, en 1970, a 90\% en la educación básica y a $49 \%$ en la enseñanza media (Cox, 2001).

La forma de impulsar estos cambios y logros fue a través del crecimiento del Ministerio de Educación Pública, cuando se posiciona y consolida el Estado docente, garante de la educación, pero, tal como lo hemos afirmado previamente, la provisión mixta continuó, tanto a nivel escolar como superior.

CUADR0 3. Matrícula básica y media por tipo de dependencia, años 1970-1988

\begin{tabular}{|l|c|c|c|c|c|}
\hline \multicolumn{1}{|c|}{ Dependencia } & 1970 & 1973 & $1980^{*}$ & 1985 & 1988 \\
\hline Fiscal/Municipal & $\begin{array}{c}1954789 \\
(78.5 \%)\end{array}$ & $\begin{array}{c}2023567 \\
(78.1 \%)\end{array}$ & $\begin{array}{c}2169023 \\
(79.1 \%)\end{array}$ & $\begin{array}{c}1817132 \\
(65.9 \%)\end{array}$ & $\begin{array}{c}1664326 \\
(60.0 \%)\end{array}$ \\
\hline Particular & & & 393480 & 778341 & 924495 \\
subvencionado** & - & - & $(14.2 \%)$ & $(28.3 \%)$ & $(33.4 \%)$ \\
\hline \multirow{2}{*}{ Particular pagado } & 534308 & 567775 & 185810 & 160685 & 183111 \\
& $(21.5 \%)$ & $(21.9 \%)$ & $(6.7 \%)$ & $(5.8 \%)$ & $(6.6 \%)$ \\
\hline \multirow{2}{*}{ TOTAL } & 2489097 & 2591342 & 2748313 & 2756158 & 2771932 \\
& $(100 \%)$ & $(100 \%)$ & $(100 \%)$ & $(100 \%)$ & $(100 \%)$ \\
\hline
\end{tabular}

* A partir de 1980, el Sistema Fiscal pasa a ser Municipalizado.

** En la categoría Particular Subvencionado se incluye a las Corporaciones (instituciones que reciben aportes fiscales anuales fijos establecidos por contrato).

Fuente: Cox y Jara, 1989.

Como podemos observar, en Chile se cumplía cabalmente el principio de libertad de enseñanza, fundamentalmente por el poder de las élites gobernantes y la influencia y el poder histórico de la iglesia católica (pugna encargada entre los partidos conservador y liberal). Esta fórmula de provisión mixta funcionó bastante bien hasta la década de los ochenta, cuando surgieron los primeros cuestionamientos de jóvenes liberales. 


\section{LA REFORMA EDUCATIVA DE LA DICTADURA (1973-1989)}

Los cambios introducidos al sistema educativo por la dictadura militar a principios de los ochenta, no solo giraron en torno a una institucionalidad y su forma de organización, sino incluso a niveles discursivos y de concepciones políticas e ideológicas, lo que significó un cambio de narrativa educativa de una tipo "Centroestatista", a una "competitiva o de mercado" (Corvalán, 2013).

Las transformaciones que introdujo la dictadura militar en el sistema educativo tenían como foco la regulación de la educación por medio del mercado y la reducción del aparato estatal por cuestiones ideológicas. La justificación de tales medidas proviene de la escuela de economía de Chicago y sus cuestionamientos hacia la educación pública, en cuanto monopolio, arguyendo que la mala calidad educativa en los EEUU era producto del monopolio de la educación por parte del Estado, que imposibilitaba la competencia para incentivar el mejoramiento (Chubb y Moe, 1999; Jofré, 1988); en cambio, si entran actores privados, motivados por la posibilidad de obtener una ganancia, esto hará (en teoría) que ofrezcan proyectos educativos diversos y de mejor calidad, obligando a la educación pública a mejorar. Bajo esta lógica, se introdujeron los siguientes cambios al sistema educativo chileno:

- Terminar con el financiamiento por escuela, dando paso a las subvenciones por alumno. Estas subvenciones son iguales, independientemente del tipo de escuela o alumno.

- Posibilidad de lucro por parte de los sostenedores de los establecimientos particulares, ya sea subvencionados con fondos públicos o sin estos.

- Se deja estipulado por ley la posibilidad de que los apoderados puedan aportar dinero; esto es conocido como "financiamiento compartido", medida que comenzó a operar de manera plena a partir de 1993.

- Los profesores dejan de ser funcionarios públicos y pasan a ser trabajadores regidos por las reglas del mercado, con lo que pierden una serie de condiciones laborales propias de los funcionarios públicos y que (dentro de las consecuencias) deriva- 
ron en la denominada "deuda histórica".

- Profunda descentralización del sistema educativo, pasándolo del Estado a los municipios.

La lógica de dicho sistema tenía dos frentes: por un lado, el traspaso de la educación pública a los municipios, que tuvo que hacerse cargo de los establecimientos educacionales públicos, sin contar con las facultades ni los recursos (humanos y monetarios) a través de las Corporaciones Municipales o los Departamentos de Administración de la Educación Municipal. El propósito de dicha descentralización era, en términos discursivos, "acercar la solución de los problemas sociales a las necesidades de la gente y obtener así soluciones más pertinentes, oportunas, rápidas, con menor burocracia administrativa" (Bertoglia, Raczynski y Valderrama, 2011: 6-7).

El segundo ámbito de esta reforma es el cambio de un Estado docente a una educación regida por el mercado; esta lógica permitiría mejorar la calidad por la competencia y tener el incentivo del lucro.

Las reformas llevadas a cabo durante la dictadura militar tuvieron como propósito -con resultados positivos- mercantilizar el sistema educativo; por mercantilización entendemos que la educación se regula bajo las lógicas de mercado y no bajo patrones estatales-burocráticos. La consecuencia de dicho proceso -como veremos a lo largo de este artículo- es que la educación pública entra en un juego de competitividad y elección mercantil donde la calidad y resultado educativo se encuentran determinados tanto por el capital económico con que cuentan las familias y las escuelas, como por capitales simbólicos (para el caso chileno, cuando se paga por un servicio es percibido como de mejor calidad que el que se encuentra disponible de forma gratuita), terminando por configurar un sistema no solo desigual en oportunidades, sino también segregado socioeconómicamente.

Como históricamente se ha constatado, la educación pública ha cohabitado con la educación particular (privada y/o subvencionada). Es importante tener esto en consideración, con lo que ha señalado la sociología, y en particular, la sociología post-estructuralista francesa (Bourdieu, Foucault, Dubet, Latour, etc.) 
acerca de que "lo real es relacional". Cuando se señala que la realidad es relacional se habla de que un actor, sistema u organización no pueden ser concebidos sin los otros actores con los que se relacionan, bien de manera colaborativa, bien en oposición. En este caso, la educación pública, tanto sus éxitos como sus fracasos tienen directa relación con la forma en cómo convive con la educación privada, es decir, la importancia que socialmente (por medio del Estado y la sociedad) se le otorga a una u otra.

Cuando la educación pública fue más fuerte (1850-1981), implícitamente existía un actor que era "más debil", que era la educación privada con subvención, y eso se traducía en la forma de pago a los profesores, la cantidad de subvención que se le entregaba a los colegios particulares versus a los estatales, la forma que tenían estos para formar una institución, etc. Lo que -implícita o deliberadamente- se hizo en la Dictadura militar con la educación pública fue ponerla en desventaja con respecto a la particular subvencionada. Todos los establecimientos educacionales subvencionados reciben igual monto por alumno matriculado y con asistencia regular, pero aquellos que pertenecen al sector Particular Subvencionado pueden cobrar un copago a los apoderados (compromiso obligatorio desde 1993), seleccionar a los estudiantes que ingresan y contar con una mayor flexibilidad en el uso de los recursos financieros y humanos.

Si concebimos el sistema educativo como un conjunto de actores que siempre se relacionan entre sí ("lo real es relacional"), podremos entender el deterioro continuo de la educación pública y de cómo es necesario, junto a un cúmulo de reformas, establecer nuevas reglas del juego para dar una mayor importancia a la educación pública, si es lo que se quiere.

Con base en esta arquitectura del sistema educativo chileno (obra de la dictadura militar), a continuación se describen y analizan las consecuencias de este diseño, las políticas educativas que se han implementado y como ha sido esta "convivencia" entre la educación pública y la privada, a fin de determinar si, efectivamente, en Chile ha existido o existe una opción porque la educación pública tenga el espacio y la valoración que antiguamente tuvo. 


\section{La descentralización del sistema educativo chileno}

\begin{abstract}
Es necesario asumir la enorme heterogeneidad de las más de 300 comunas en Chile, en tamaño, población, ubicación geográfica, recursos y presupuesto anual, entre otros aspectos. Tal heterogeneidad hace francamente inviable que todas ellas puedan contar con los recursos, financieros y técnicos necesarios para ofrecer procesos educativos de calidad...
\end{abstract}

(Román, 2007: 149)

La decisión en materia de política educativa acerca de contar con sistemas educativos centralizados o descentralizados ha sido solucionada en parte. En general, en países europeos tales como Holanda, Finlandia y Bélgica, las escuelas, sean privadas subvencionadas o públicas, cuentan con altos grados de libertad para la administración de recursos e innovaciones curriculares (a partir de mínimos establecidos por los ministerios de educación respectivos). Estas libertades parten de un sistema con reglas del juego justas, que se encuentran orientadas a impedir que se repliquen las desigualdades sociales, pero a su vez, las libertades son posibles debido a estándares o normas orientadas a que en las escuelas existan altas capacidades de liderazgo, administración de recursos, empoderamiento, redes de coordinación y aprendizaje y una formación docente y continua de excelencia (Bellei y Trivelli, 2014).

En Chile, durante la dictadura militar se traspasó la administración de la educación pública a los municipios con el propósito de que la educación tuviese un anclaje mucho mayor a las comunidades y, a la vez, para que la respuesta a las necesidades de cada escuela fuesen satisfechas de manera rápida. El problema de este traspaso de la educación pública fue no contemplar la gran heterogeneidad de municipios y, también los recursos de los mismos, es decir, al igualar la subvención entre las escuelas públicas y privadas, no se previó que las escuelas públicas iban a tener, mayoritariamente, una matrícula proveniente de estratos vulnerables, por lo que los recursos para educar a dichos alumnos eran (y son) escasos, y es necesario aumentar los humanos tanto como financieros, para que puedan funcionar de manera correcta. Entonces, a pesar de que se generó un sistema descentralizado, este solo fue beneficioso para el ministerio, ya que, en la práctica, no se 
otorgaron las facultades para que tanto los sostenedores públicos (municipalidades a través de las corporaciones municipales o las Direcciones de Administración de Educación Municipal (DAEM) como las escuelas llevaran a cabo procesos educativos; tampoco hay figuras claras a quienes puedan los directores de escuela acudir en materia de procesos técnico-pedagógicos, mientras que el Estatuto Docente también ha jugado en contra.

Aspectos positivos (teóricamente) sí han existido; si bien el traspaso hacia un sistema descentralizado ha sido traumático para la escuela pública y las municipalidades (por la competencia desigual a la que se ven enfrentadas), se valoran el intento de otorgar con el tiempo los nuevos grados de autonomía de las escuelas y las municipalidades para fiscalizar y administrar, la posibilidad de dar respuesta rápida a necesidades materiales y también de recibir apoyos técnicos que anteriormente eran extremadamente lentos. También son profundamente valorables los grados de democratización (insuficientes aún), que se ha logrado introducir al interior de las escuelas (Román, 2007).

Tener un sistema descentralizado parcial y defectuoso, sumado a un sistema educativo organizado y regulado por un "cuasi-mercado", lo cual ha aumentado las desigualdades y la segregación, llevó a que en 2006 emergiera una de las mayores movilizaciones sociales desde la vuelta a la democracia. El movimiento estudiantil posicionó la demanda no tan solo de un sistema educativo no-mercantil, sino que demandó también una nueva forma de organización del sistema educativo que permitiera generar un realce de la educación pública (demandas nuevamente presentadas en el movimiento estudiantil de 2011). Es a partir de los diagnósticos y demandas que genera el movimiento estudiantil (sumado a la evidencia acumulada durante dos décadas de este sistema educativo) que se genera una propuesta nueva de descentralización de la educación pública que viene a presentar algunas soluciones al modelo existente.

\section{Políticas de Focalización (1990-2000)}

Luego de la vuelta a la democracia, las políticas implantadas hacia el sistema educativo fueron las llamadas de mejoramiento escolar 
y de focalización. La justificación para que se realizaran este tipo de políticas fue la ausencia de necesidad de realizar una reforma sistémica, debido a que no existían datos acerca de la nueva organización del sistema y, al mismo tiempo, un clima de transición en el que la clase política buscaba mantener un ambiente político de paz (Picazo Verdejo, 2013).

Estas políticas se diseñaron a partir, fundamentalmente, de los datos que entregaba el Sistema de Medición de la Calidad Educativa (SIMCE), los cuales alertaron acerca de la poca efectividad del sistema en cuanto al logro en los sectores más vulnerables del país. Los datos que entregaba este sistema de medición permitieron la creación del programa P900; más tarde el Programa de Mejoramiento de la Calidad y Equidad de la educación en Escuelas básicas y, posteriormente, en las de enseñanza media (MECE). Dicho programa se focalizaba en la entrega de insumos educativos, y se propuso como meta mejorar la cobertura y calidad tanto en educación parvularia como en educación básica.

En 1991, se elaboró el Estatuto docente (Ley núm. 19.070) para mejorar la precaria condición en que se encontraba la profesión docente, reglamentando aspectos de contratación, condiciones, derechos y deberes laborales, así como la creación de un sistema de evaluación docente y la llamada carrera profesional docente.

Durante la segunda mitad de la década de 1990 (Gobierno de Eduardo Frei Ruiz Tagle, 1994-2000), se conformó una comisión cuyo propósito fue diseñar las políticas educativas hacia el futuro; las propuestas de esta comisión giraron en torno a cuatro dimensiones, 1. continuar las políticas de focalización y mejoramiento continuo, 2. políticas de apoyo y fortalecimiento a la profesión docente (políticas de incentivos monetarios), 3. una reforma curricular, y por último, 4. aumento de la jornada escolar por medio de la llamada "Jornada Escolar Completa" (JEC) (Cox, 2003).

Una de las pocas políticas igualitarias implantadas hacia finales de los noventa tuvo como fin último la "igualación" del capital cultural entre los alumnos provenientes de diferentes niveles socioeconómicos y que ha sido un gran logro para reducir en parte (muy acotada) las desigualdades sociales al interior del 
sistema educativo (Maugner, 2012) fue, justamente, la Jornada Escolar Completa (JEC). Factor similar fue el caso de la extensión de la obligatoriedad de la educación hasta el $4^{\circ}$ medio durante el gobierno de Ricardo Lagos, medida que no solo permitió tener igualdad de resultados hasta cierto nivel educativo, y eliminar el alto porcentaje de deserción escolar, sino la posibilidad de eliminar desigualdades de ingreso a la educación superior, dado que ahora muchos alumnos provenientes de estratos socioeconómicos más bajos, al terminar la educación media, estaban en condiciones de postularse a carreras en la educación superior.

Durante la década de 2000 se comenzaron a evaluar y analizar los resultados de las pruebas SIMCE, una vez implementadas las reformas de la década anterior. Los resultados mostraron un nulo progreso en la comparación entre las cohortes de alumnos. Una de las explicaciones fue que el Estatuto Docente impedía la eliminación de profesores mediocres, estancando la calidad (Fontaine y Eyzaguirre, 2001). Junto con la obligatoriedad de la enseñanza media (completando 12 años de enseñanza obligatoria para los alumnos del sistema educativo), y un sistema de evaluación docente, no se diseñaron más políticas.

Antes de continuar con la exposición de las políticas educativas posteriores a 2008, presentamos un estado de la educación pública chilena, mediante datos sobre la desigualdad y la segregación del sistema educativo.

\section{ESTADO DE LA EDUCACIÓN PÚBLICA EN CHILE}

\section{Desarrollo y consecuencias de la arquitectura del sistema educativo: desigualdad y segregación}

Durante las últimas décadas, la educación pública en Chile ha experimentado un proceso de deterioro que se expresa, en primer lugar, en la baja sostenida de matrícula en relación con la matrícula de los establecimientos particulares subvencionados (Gráfica 1). 
GRÁFICA 1. Evolución de la matrícula en el sistema público vs sistema privado, periodo $1965-2010$

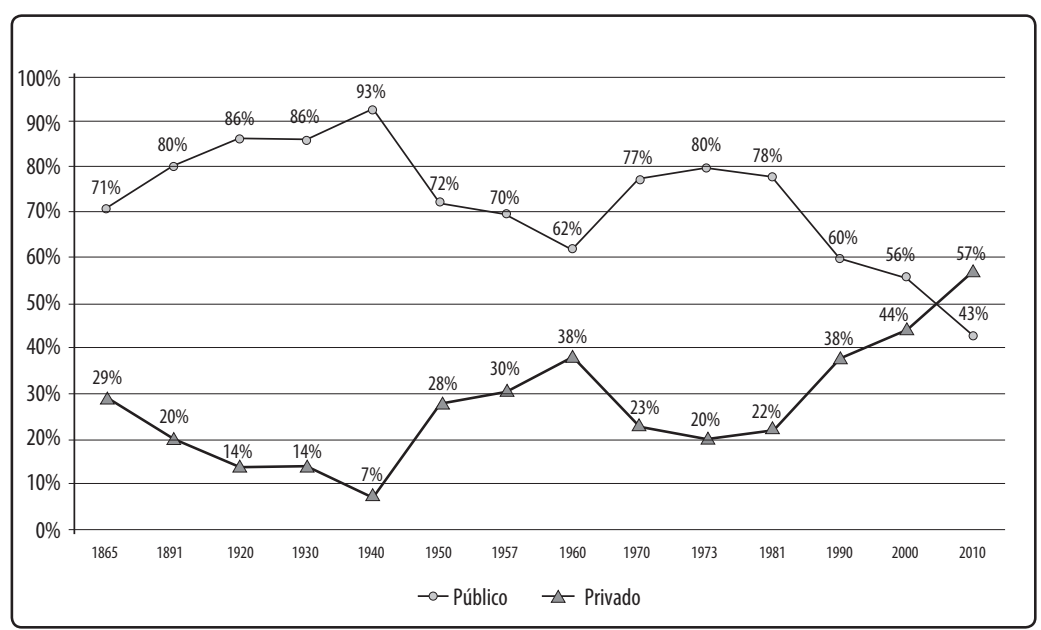

Fuente: Elacqua, $2013 .^{1}$

En la gráfica anterior podemos ver el desplome de la matrícula de la educación pública versus el crecimiento de la educación particular subvencionada a partir de 1973. Los motivos que explican esta caída son varios; por ejemplo, la posibilidad de distinguirse socialmente de la desprestigiada educación pública (municipal), y ciertos elementos, como la supuesta mejora en la infraestructura, el equipamiento y la calidad educativa que ofrecen las escuelas particulares subvencionadas (PS).

Un hecho que desmiente la supuesta superioridad de la educación PS por sobre la municipal es que, según los resultados arrojados por el Sistema de Medición de la Calidad de la Educación (SIMCE), ${ }^{2}$ en 2013, en matemáticas y en la Región Metropolitana, $50 \%$ de los peores resultados los obtienen los establecimientos

\footnotetext{
1 Presentación de Gregory Elacqua ante la cámara de diputados, disponible en http:// bicentenario.camara.cl/seminario/pdf/mesa\%204\%20-\%20Gregory\%20Elacqua.pdf

${ }^{2}$ El SIMCE es un test estandarizado diseñado e implementado desde mediados de la década de los ochenta. Sus pretensiones son: 1) informar a los apoderados acerca de la calidad del colegio por medio del logro de aprendizajes en determinadas materias curriculares, y 2) fuente de información para el Ministerio de Educación que le permite fiscalizar acerca de la calidad de los establecimientos. Desde hace un par de años viene con fuertes críticas por su visión reducida acerca de la "calidad de educación que entregan los establecimientos", someter a presiones y malas prácticas a los establecimientos y ser un incentivo negativo para las escuelas.
} 
particulares con subvención estatal, ${ }^{3}$ lo que muestra claramente que los establecimientos particulares subvencionados no entregan necesariamente una mejor educación (Hsieh y Urquiola, 2006). Es importante dar cuenta de los reales motivos de esta fuga de matrícula, ya que no es debido a mejoras en la calidad de la educación; esto ha sido comprobado al controlar la variable del nivel socioeconómico de los alumnos en las pruebas SIMCE, mostrándose que los resultados entre los establecimientos particulares subvencionados no son significativamente mejores que los municipales (Cuadro 3).

CUADRO 4. Rendimiento SIMCE $8^{\circ}$ básico según grupo socioeconómico y dependencia

\begin{tabular}{|c|c|c|c|c|}
\hline & \multirow{2}{*}{$\begin{array}{c}\text { Grupo } \\
\text { socioeconómico }\end{array}$} & \multicolumn{3}{|c|}{ Puntaje promedio 2013, diferencia entre dependencias } \\
\hline & & Municipal & Particular subvencionado & Particular pagado \\
\hline \multirow{5}{*}{$\begin{array}{l}\text { Comprensión de } \\
\text { lectura }\end{array}$} & Bajo & 237 & 238 & \\
\hline & Medio bajo & 238 & $(+) 245$ & \\
\hline & Medio & 256 & 259 & \\
\hline & Medio alto & $(+) 287$ & 274 & \\
\hline & Alto & & 283 & (+) 289 \\
\hline \multirow{5}{*}{ Matemática } & Bajo & 236 & 234 & \\
\hline & Medio bajo & 241 & $(+) 250$ & \\
\hline & Medio & 261 & $(+) 267$ & \\
\hline & Medio alto & (+) 300 & 286 & \\
\hline & Alto & & 299 & $(+) 312$ \\
\hline \multirow{5}{*}{ Ciencias naturales } & Bajo & 248 & 248 & \\
\hline & Medio bajo & 253 & $(+) 261$ & \\
\hline & Medio & 272 & $(+) 278$ & \\
\hline & Medio alto & (+) 305 & 296 & \\
\hline & Alto & & 308 & $(+) 316$ \\
\hline
\end{tabular}

Fuente: Mineduc, 2014.

En el Estudio Nacional de Opinión Pública CEP (Centro de Estudios Públicos) de 2014, ${ }^{4}$ en el módulo educación, casi $60 \%$ de los encuestados prefiere poner a sus hijos en un colegio particular subvencionado (Gráfica 2). Este dato, sumado al anterior corroboran la tesis de que -a no ser que el establecimiento particular subvencionado cobre un co-pago superior a los 50

\footnotetext{
${ }^{3}$ Véase http://www.latercera.com/noticia/nacional/2014/10/680-601898-9-el-50-de-loscolegios-con-mas-bajo-resultado-en-simce-es-subvencionado.shtml

${ }^{4}$ Independiente de los problemas que esta tuvo en su aplicación y cambios en los cuestionarios que generaron una polémica, los datos no revisten mucha distancia con la realidad.
} 
mil pesos- lo que finalmente eligen las familias es la "distinción social", es decir, escapar de la mezcla de sus hijos con los hijos de familias provenientes de estratos más vulnerables, tal como lo explicita una apoderada entrevistada por un diario quien señala que "No me gusta esta reforma, porque todos los niños van a estar mezclados". 5 Esto se corresponde con lo que muestran los datos de la encuesta CIDE a actores del sistema educativo, donde se constata que a pesar de que los resultados no mejoran, los apoderados prefieren hacer un co-pago a las escuelas de sus hijos (Corvalán, 2003).

\section{GRÁFICA 2. Preferencia hacia un determinado tipo de establecimiento a similar costo y distancia*}

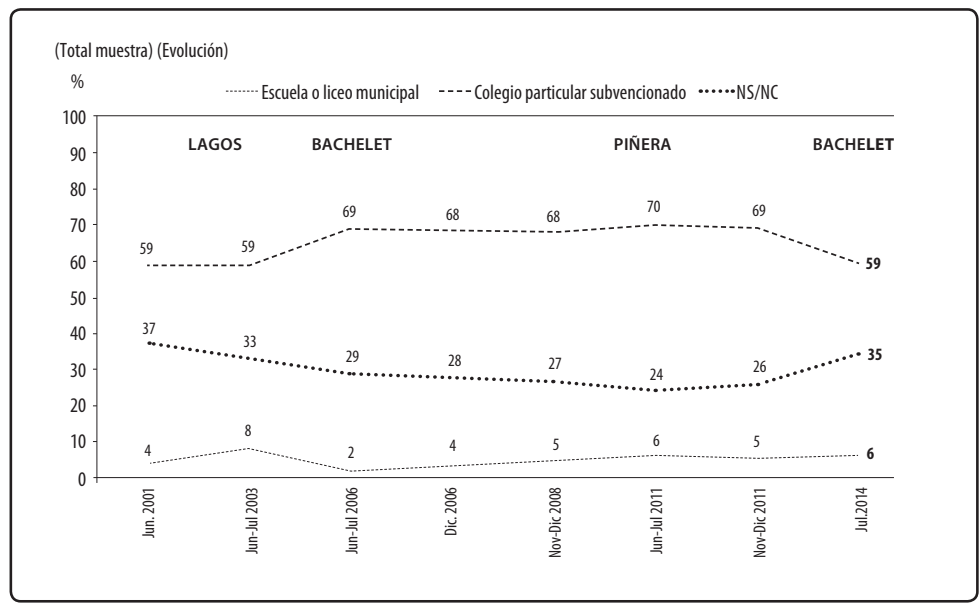

*A igual costo de matrícula y similar distancia, ¿Ud. preferiría una escuela o liceo municipal o un colegio particular subvencionado?

Fuente: Centro de Estudios Públicos, 2014.

Es importante considerar que los sistemas sociales -como el educativo- son relacionales, es decir, el cambio de una de las partes afecta a las otras. La matrícula que se fuga de los establecimientos públicos emigra principalmente hacia establecimientos particulares subvencionados (los cuales pueden lucrar, seleccionar y/o cobrar financiamiento compartido). La composición de

\footnotetext{
${ }^{5}$ La Tercera, Sección Nacional, "Apoderados realizan masiva marcha por la Alameda y se comparan con estudiantes”, domingo, 26 de octubre de 2014.
} 
los alumnos que puede emigrar debido a las trabas de selección ${ }^{6}$ tienen lo que Pierre Bourdieu ha denominado como ciertos capitales que les permiten la distinción social y, por ende, promueven la desigualdad social. Estos capitales son: el capital cultural (la cantidad de conocimientos, años de estudio, libros, experiencias, etc.), el capital social (las redes de contactos, participación en grupos sociales, etc.) y el capital económico (Bourdieu, 2007); también se expresan en ciertos atributos que buscan las escuelas como tener familias de una determinada creencia religiosa o no tener estudiantes con necesidades educativas especiales, etcétera.

Dado que los alumnos que pueden emigrar a las escuelas particulares subvencionadas son los que poseen familias con mayor capital económico, cultural y social, la composición del alumnado de las escuelas municipales se va integrando, principalmente, por alumnos que provienen de estratos vulnerables; este proceso es lo que la literatura especializada ha llamado el descreme de estudiantes. El estudio “¿Qué hacer con la educación municipal?” del Centro de Políticas Públicas de la PUC (2011), afirmó que "esta competencia desigual ha conducido a que sean los establecimientos municipales los que reciban a gran proporción de los estudiantes vulnerables. Ha contribuido, además, a la deslegitimación de la educación pública, para cuyo fortalecimiento y revitalización es importante incorporar una mirada integral al sistema"(Centro de Políticas Públicas UC, 2011: 15).

Los datos permiten no solo comprobar la composición socioeconómica de los establecimientos públicos, sino también su rendimiento en las pruebas estandarizadas. En la gráfica 3 se muestra cómo Chile posee el mayor índice de DUNCAN, ${ }^{7}$ el cual mide el grado de segregación socioeconómica (0 indica que no existe segregación y 1 es la existencia plena de segregación) entre 57 países. Es importante constatar que este ha aumentado en el

\footnotetext{
${ }^{6}$ La selección en el sistema educativo chileno es por tres motivos: 1) por nivel socioeconómico en el que se pide a los padres un pago mensual, cuota de incorporación, etc.; 2) ajuste al proyecto educativo; este motivo donde se pide a los padres certificados religiosos, determinadas habilidades a los niños, etc.; y 3) por motivos académicos.

${ }^{7}$ El Îndice de Duncan (creado por Duncan y Duncan) mide la proporción de individuos que se ubican en un determinado grupo y que deben ser traspasados a otro para lograr una distribución igualitaria. El índice fluctúa entre 0 y 1 , siendo 0 muy igual y 1 muy segregado. (Duncan y Duncan, 1995).
} 
tiempo entre $30 \%$ de alumnos de nivel socioeconómico superior y $30 \%$ de alumnos de nivel socioeconómico inferior (Bellei, 2013).

GRÁFICA 3. Segregación escolar en los países a partir del Índice de Duncan

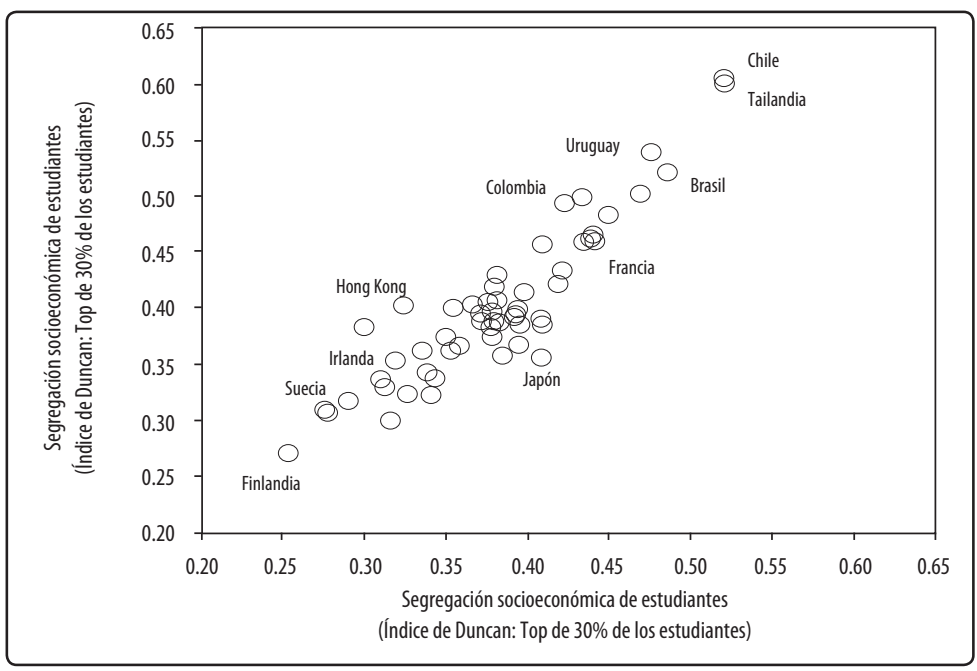

Fuente: Bellei, 2013

Si bien no existen estudios empíricos acerca de las consecuencias de la segregación (tanto académica como socioeconómica) (Bellei, 2015), la evidencia indirecta nos indica que el denominado "efecto par" cobra gran importancia para explicar el éxito o el fracaso escolar; en otras palabras, el tener establecimientos con una composición homogénea de alumnos que provienen de estratos vulnerables (con familias con menor capital cultural, social y económico) -sumado a otros factores que más adelante se procederá a mostrar- genera que el éxito de los alumnos se encuentre muy asociado a su condición socioeconómica. Es decir, es altamente probable (y los datos de las pruebas estandarizadas así lo indican) que los alumnos pobres que estudian en escuelas con alumnos de su misma condición socioeconómica obtengan bajos puntajes SIMCE, tengan menores posibilidades de seguir estudios superiores debido a los bajos puntajes obtenidos en la Prueba de 
Selección Universitaria ${ }^{8}$ (PSU) y, por ende, se sigue una reproducción de la desigualdad social (la cual posteriormente repercute en el mercado laboral).

A su vez, la segregación atenta contra uno de los principios normativos fundamentales de los sistemas educativos que es la generación de cohesión social, ya que al segregar a la población estudiantil y determinar sus resultados, se genera un clima de malestar social, prejuicios y conflictos entre clases sociales.

En la siguiente gráfica se puede observar el comportamiento de los puntajes SIMCE promedio por dependencia en $4^{\circ}$ básico y en Lectura. Si bien la brecha entre el sector particular pagado y el municipal ha disminuido en 10 puntos entre 2005 y 2013, no deja de llamar la atención la estratificación que se mantiene estable con los años.

\section{GRÁFICA 4. Tendencia resultados SIMCE $4^{\circ}$ básico en lectura, según tipo de establecimiento, 2005-2013}

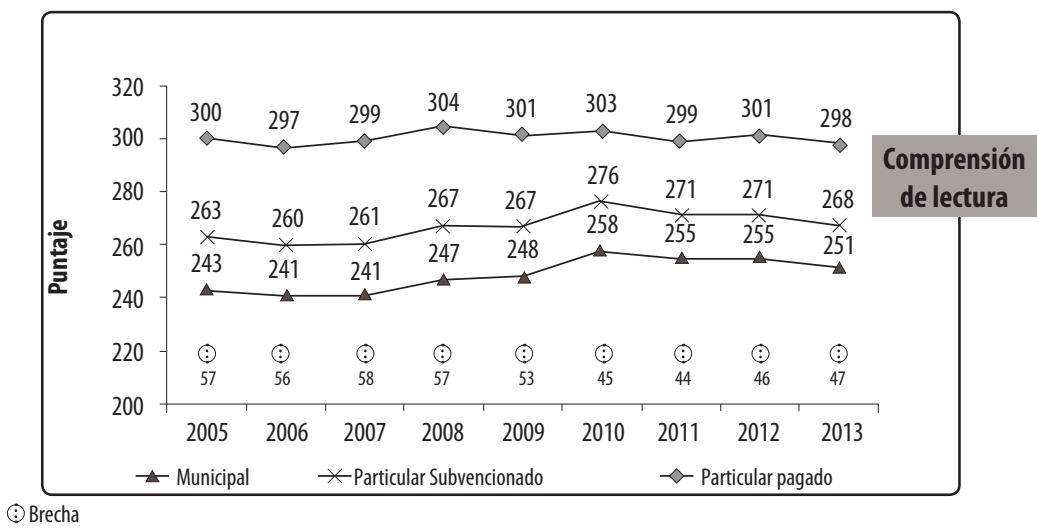

Fuente: Mineduc, 2013.

Lo mismo ocurre en la Prueba de Selección Universitaria, que selecciona a los alumnos por medio de un puntaje para determinar su ingreso a determinadas instituciones de educación superior y a las carreras, finalmente, termina siendo una representación de las desigualdades sociales y de la segregación del sistema

\footnotetext{
${ }^{8}$ La Prueba de Selección Universitaria es un test estandarizado y habilitante para el ingreso a la educación superior que se comenzó a aplicar en 2003.
} 
educativo (cuadro 5). Pero en un nivel más profundo, al ser el mecanismo que permite el ingreso a la educación superior y, por ende, al mundo laboral, se reproducen las desigualdades sociales (Kremerman, 2007; OECD, 2009).

CUADRO 5. Resultados PSU según tipo de dependencia y modalidad, 2013

\begin{tabular}{|c|c|c|c|c|c|}
\hline & & PSU-L & PSU-M & PSU-H & PSU-C \\
\hline \multirow{3}{*}{ Dependencia } & Municipal & $\begin{array}{c}469 \\
(107)\end{array}$ & $\begin{array}{c}468 \\
(103)\end{array}$ & $\begin{array}{c}473 \\
(106)\end{array}$ & $\begin{array}{c}472 \\
(104)\end{array}$ \\
\hline & P. Subvencionado & $\begin{array}{c}501 \\
(101)\end{array}$ & $\begin{array}{c}500 \\
(101)\end{array}$ & $\begin{array}{c}501 \\
(101)\end{array}$ & $\begin{array}{c}499 \\
(100)\end{array}$ \\
\hline & P. Pagado & $\begin{array}{l}602 \\
(98) \\
\end{array}$ & $\begin{array}{c}612 \\
(102) \\
\end{array}$ & $\begin{array}{c}601 \\
(102) \\
\end{array}$ & $\begin{array}{c}602 \\
(103) \\
\end{array}$ \\
\hline \multirow{2}{*}{$\begin{array}{l}\text { Rama } \\
\text { (Modalidad) }\end{array}$} & Científico Humanista & $\begin{array}{c}521 \\
(109) \\
\end{array}$ & $\begin{array}{c}521 \\
(111)\end{array}$ & $\begin{array}{c}524 \\
(109) \\
\end{array}$ & $\begin{array}{c}517 \\
(108)\end{array}$ \\
\hline & Técnico Profesional & $\begin{array}{l}449 \\
(89)\end{array}$ & $\begin{array}{l}447 \\
(85)\end{array}$ & $\begin{array}{l}455 \\
(92)\end{array}$ & $\begin{array}{l}436 \\
(84)\end{array}$ \\
\hline
\end{tabular}

Fuente: Educación, 2020.

Los datos presentados de SIMCE y PSU plantean un desafío a largo plazo para la educación pública: ¿cómo atraer a las familias y a los alumnos de mayores capitales sociales, culturales y económicos nuevamente? Como ya hemos señalado, esto se transforma en una necesidad imperante del sistema para alcanzar los efectos positivos que podría generar para los alumnos vulnerables el hecho de compartir la misma sala de clases con alumnos más beneficiados (la literatura especializada defiende esto mediante el conocido efecto par o pairs effect). Por otra parte, una composición heterogénea de las escuelas podría conducir a mostrar cómo lo está haciendo efectivamente cada establecimiento, es decir, la real calidad educativa que entrega (Araya et al., 2015; Carrasco et al., 2014).

\section{Docentes, directores y mercado}

Junto con la composición del alumnado (aclaramos que el problema no es que sea vulnerable, sino que lo es la falta de heterogeneidad, tanto académica como social de dichos establecimientos) 
de los establecimientos públicos, diversos estudios dan cuenta de otros problemas que han contribuido al deterioro de la educación pública, como lo son las condiciones laborales de los profesores, la selección de directores, el financiamiento y la organización de estas escuelas (Bellei et al., 2014 y UNICEF, 2004).

El motivo, a juicio nuestro, no es solo el hecho de que los establecimientos públicos cuenten con docentes con bajo nivel (como ocurre con un alto porcentaje de escuelas particulares subvencionadas), sino porque el Estado no ha tomado una postura clara en torno a la importancia que quiere dar a la educación pública; en lugar de tomar una postura, deja en manos del mercado la distribución de los docentes, según las capacidades económicas y simbólicas de las escuelas. Con esto, tanto los docentes como los directores tenderán a buscar en el mercado de escuelas, aquellas mejores ofertas tanto en lo económico como en lo profesional. Nuevamente, las escuelas particulares subvencionadas están en una posición de ventaja, dado que tienden a contar con mayor matrícula, mejor infraestructura, y niños seleccionados (descremados), según su rendimiento académico, nivel socioeconómico o tipo de familia. De esta forma, los cursos conformados son menos problemáticos en el sector PS, mientras que en las escuelas públicas, al no poder seleccionar ni cobrar, se quedan con el resto de la matrícula (los de bajo rendimiento y menores ingresos).

En los estudios Lo aprendi en la escuela (Bellei et al., 2014) y ¿Quien dijo que no se puede? (UNICEF, 2004) se señala que contar con un buen clima en la escuela, directores con liderazgo, una descentralización adecuada, buenos profesores y en condiciones óptimas y una adecuada organización de la comunidad educativa en su conjunto permiten buenos resultados, independientemente de la composición socioeconómica de la matrícula. Todos estos aspectos cruciales para el buen desempeño de una escuela se han dejado en manos de la lógica del mercado, es decir, la distribución de docentes y directivos, así como sucede con la distribución de alumnos, se encuentran fundamentalmente determinadas por las capacidades económicas, y no así por una planificación o criterio de regulación central.

Para el caso de los docentes, existe un consenso con base en la evidencia que las condiciones laborales de los profesores 
en Chile y su formación (en la mayoría de las instituciones de educación superior) no son óptimas. Bajas remuneraciones, horarios agobiantes, poco tiempo para la familia y mala calidad de las instituciones formadoras han hecho que la calidad docente, en general, sea baja. Si bien todos estos factores impactan indistintamente a gran parte del sistema educativo, independiente del tipo de establecimiento del que hablemos (municipal, particular subvencionado y particular pagado), debido al funcionamiento del financiamiento de las escuelas y los discursos sociales en torno a estas, la calidad de los docentes y sus condiciones laborales varían según el tipo de establecimiento y su composición socioeconómica. Tal como hemos puesto en evidencia, las condiciones del juego, es decir, la forma en cómo se encuentra organizado el sistema educativo permite que las escuelas particulares (subvencionadas y no subvencionadas) tengan reglas que las favorecen y puedan, en ciertos casos, contratar a mejores docentes, tal como lo demuestran los siguientes gráficos:

GRÁFICA 5. Distribución de mejores y peores resultados en prueba INICIA en escuela de distinto nivel socioeconómico. Años 2008-2009

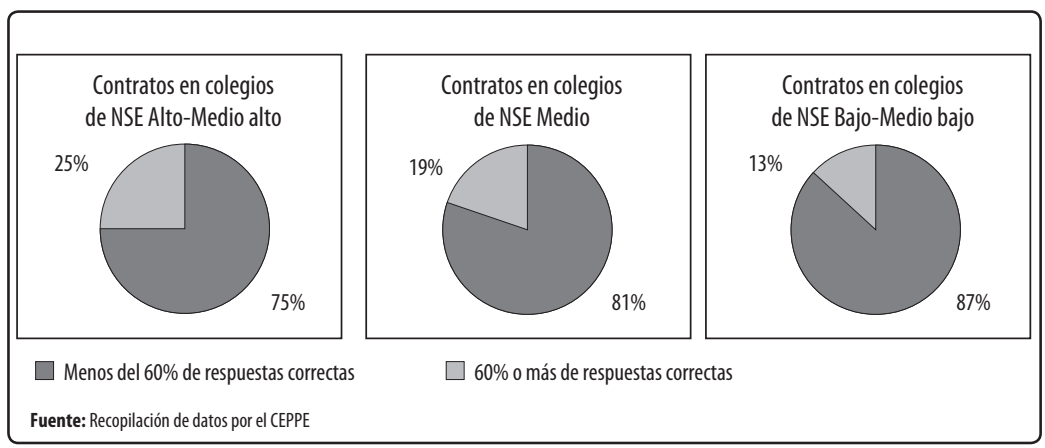

Fuente: Cox, C., 2011.

Según los datos del CEPPE presentados por Cox (2011), "los profesores de más bajo rendimiento en las pruebas INICIA se insertan en mayor proporción en las escuelas de nivel socioeconómico bajo o medio bajo (escala SIMCE)" (Cox, 2011: 5). En los establecimientos educacionales de niveles socioeconómicos alto-medio alto, 25\% de los docentes responde más de $60 \%$ de 
respuestas correctas; en cambio, en los colegios de niveles socioeconómicos bajos el porcentaje de docentes con más de $60 \%$ de respuestas correctas solo es de $13 \%$.

El estatuto docente ha sido indicado como una de las piedras de tope para el recambio de la planta docente de la educación pública (Román y Carrasco, 2007). Si bien este código legal para los profesionales de la educación ha permitido avanzar en estabilidad laboral, las regulaciones impiden el despido de profesores que llevan largo tiempo en las escuelas públicas y con bajos rendimientos, lo que no permite la entrada de nuevos docentes. En palabras de Marcela Román y Álvaro Carrasco (2007), "Las municipalidades tienen un estrecho margen para contratar, despedir y mover a los profesores debido a las excesivas protecciones que se establecen en el Estatuto Docente. A juicio de la totalidad de los entrevistados, estas limitaciones constituyen uno de los obstáculos más importantes para los esfuerzos por mejorar la calidad de la educación" (Román y Carrasco, 2007: 16).

La calidad de los profesores es fundamental a la hora de potenciar un sector educativo; nuevamente volvemos a nuestra tesis de que los sistemas sociales se componen de unidades relacionales; por lo tanto, para que uno tenga lo mejor, lo otro tiene que tener algo que no es "tan bueno". En el caso de los docentes, si se quiere una educación pública fuerte y "mejor" o igual que la educación particular subvencionada, se necesita que los mejores docentes se encuentren en este sector; la generación de políticas de incentivos para atraer a los mejores docentes se presenta como una necesidad urgente, así como la re-estructuración del estatuto docente y la mejora de las condiciones laborales. En países como Bélgica, Holanda o Suecia los profesores son funcionarios públicos o, al menos, sus sueldos son pagados por el Estado, lo que los saca de las regulaciones del mercado e impide desigualdades entre tipos de establecimientos (Bellei y Triveli, 2014).

Otra de las grandes explicaciones al bajo desempeño de las escuelas, tanto particulares subvencionadas como municipales, es que los directores no cuentan con las capacidades tanto técnicopedagógicas como de liderazgo.

Hasta el 2005, en la educación pública existían muy bajos criterios de selectividad para los directores de escuela, lo que implicó en muchos casos que personas asumían el cargo de director 
gracias a sus relaciones políticas más que a criterios técnicospedagógicos; además, durante la dictadura militar, los directores adquirían la condición de vitalicios. Si bien en 1991 se establecen los primeros concursos para la elección de directores y jefes de las Direcciones de Administración de Educación Municipal (DAEM), esto no afectó a los vitalicios y la iniciativa no fue regulada por ley. En el año 2005, se dicta la ley $N^{\circ} 20.006$, la cual establece la concursabilidad para todos los cargos de directores (incluyendo los vitalicios) y la gradualidad de su nombramiento, manteniendo el cargo con un plazo máximo de cinco años. Ya en 2011, se comienza a considerar la selección como un proceso técnico en el cual participa y apoya el "Concejo de Alta Dirección Pública", además se establece un convenio de desempeño y se modifican las remuneraciones (Ley $\mathrm{N}^{\circ}$ 20.501). Los logros de esta nueva ley son relevantes (como lo señala la tabla $\mathrm{N}^{\circ} 6$ ) pero aún se requiere seguir fomentando la concursabilidad para los cargos de directores de establecimiento y jefes DAEM.

CUADRO 6. Avance de cargos publicados y nombrados en el país

\begin{tabular}{|c|c|c|c|c|c|c|c|}
\hline & $\begin{array}{l}\text { Universo a } \\
\text { concursar }\end{array}$ & Publicados & $\begin{array}{l}\% \text { de } \\
\text { avance }\end{array}$ & Nombrados & $\begin{array}{c}\% \text { de } \\
\text { publicados }\end{array}$ & Desiertos & $\begin{array}{c}\% \text { de } \\
\text { desiertos }\end{array}$ \\
\hline Directores & 3893 & 1511 & $39 \%$ & 1087 & $28 \%$ & \multirow[b]{2}{*}{434} & \multirow[b]{2}{*}{$28.5 \%$} \\
\hline $\begin{array}{l}\text { DAEM menos } \\
\text { de } 1200\end{array}$ & 96 & 37 & $39 \%$ & 31 & $32 \%$ & & \\
\hline $\begin{array}{l}\text { DAEM más } \\
\text { de } 1200\end{array}$ & 197 & 93 & $47 \%$ & 71 & $36 \%$ & 9 & 11 \\
\hline
\end{tabular}

Fuente: Pizarro y Waissbluth, 2014: 8.

Hay que tener presente que, con el aumento de establecimientos educacionales entre 1990 y 2000, el número de directores ha aumentado considerablemente. Desde 2004 se pasó de 7249 directores a 8405 en 2010 . A su vez, en el sector municipal se encuentra el mayor porcentaje de directores con edades sobre los 50 ańos $(80.4 \%)$, mientras que en el sector particular sub-

\footnotetext{
${ }^{9}$ El consejo de "Alta Dirección Pública" es la entidad encargada de seleccionar todos los cargos gubernamentales de carácter "no político" de manera pública y transparente, donde la trayectoria educativa, laboral y técnica son los criterios fundamentales a la hora de comparar y seleccionar a los funcionarios. Más información en http://www.serviciocivil.gob.cl/ sistema-de-alta-direcci\%C3\%B3n-p\%C3\%BAblica-0
} 
vencionado más de 50\% tienen menos de 50 años (Weinstein y Muñoz, 2012).

Un dato interesante es el hecho que $99 \%$ de los directores para 2010 declaraba tener al menos un título profesional relacionado con educación, incluso existiendo altos porcentajes de directores con postgrados (cuadro 7). Ahora bien, aunque opera una distribución desigual de los títulos, en este caso es en favor de los directivos municipales, debido a que este sector es el que posee un mayor porcentaje de directivos con postítulos y directores con grado de magister (solo cuando se habla de doctorado la educación pública cuenta con directores menos formados en relación con los directores de establecimientos particulares subvencionados). Si los resultados del rendimiento de los directores no son los óptimos, entonces cabe preguntarse por la formación inicial y continua que poseen los directores, y la acreditación de esta (capacitaciones, postgrados, etcétera).

CUADRO 7. Formación de los directivos de establecimientos educacionales.

\begin{tabular}{|l|c|c|c|c|}
\hline & Total & Municipal & Particular subvencionado & Particular pagado \\
\hline Con diplomado o postítulo & 69.7 & 89.0 & 56.8 & 65.4 \\
\hline Con magíster & 44.2 & 60.6 & 31.8 & 47.9 \\
\hline Con doctorado & 4.4 & 5.0 & 3.0 & 8.8 \\
\hline
\end{tabular}

Fuente: Fernández, Franco, Carla Guazzini y Mario Rivera, 2012: 41-54.

Como podemos observar, si bien ha habido esfuerzos y logros a nivel de postulación, concursabilidad y logros, en cuanto al fortalecimiento de la labor y figura del director de escuela. Claramente existen otros factores como el clima escolar, los espacios de democracia y participación al interior de la escuela, motivación escolar, etc., en los cuales, dada la configuración del sistema, se encuentran desigualmente distribuidos en lo educativo la calidad o índices positivos de estos. 


\section{La "Revolución pingüina" de 2006 y la derogación de la LOCE}

Como afirma la Cuenta Pública 2006-2010 del Ministerio de Educación (MINEDUC, 2010), la "Revolución Pingüina ${ }^{10}$ de 2006 instaló la urgencia de modificar el ordenamiento legal del sistema educativo para garantizar una educación de calidad para todos”. El gran movimiento liderado por estudiantes secundarios motivó la conformación de un Consejo Asesor Presidencial, el cual ratificó la urgencia de reemplazar la Ley Orgánica Constitucional de Educación (LOCE por su sigla, publicada el 10 de marzo de 1990). La "Revolución Pingüina" impulsó, por primera vez en la historia reciente de Chile, la revisión de las bases del sistema educativo: el mercado, la competencia y la producción de desigualdad.

En enero de 2008, se promulgó la Ley de Subvención Escolar Preferencial, conocida como Ley SEP, la cual reconoce que se requieren más recursos para educar a los estudiantes provenientes de contextos socioeconómicos vulnerables y cuyo objetivo era "compensar las desigualdades sociales de origen que afectan a los niños y niñas de los sectores más modestos, entregando un aporte adicional a los establecimientos que los acogen y comprometiendo con ellos una estrategia de mejoramiento educativo".

En agosto de 2009, se derogó la LOCE y se promulgó la Ley General de Educación, marco legal que establece "el derecho a la educación de calidad para todos" mediante:

- El derecho universal a la educación gratuita desde el pre-kínder como uno de los principios del sistema educativo.

- Una definición de los derechos y deberes de todos los actores de la comunidad educativa.

- El establecimiento de estándares de aprendizaje y desempeño; sistemas de evaluación periódica; registros y difusión de información para asegurar la calidad del sistema.

- Requisitos más exigentes para obtener y mantener la condición de sostenedor.

${ }^{10} \mathrm{La}$ "Revolución Pingüina" es el nombre que se le dio a un gran movimiento estudiantil que comenzó el año 2006 en Chile, fue liderado por estudiantes secundarios (cuyos uniformes son blanco, gris y negro, similares a los colores del ave marina) y sus consignas fueron: Derogación de la LOCE, Fin a la educación de mercado y Fin al SIMCE. 
- Medidas de no-discriminación e inclusión de estudiantes vulnerables: Prohibición de la selección hasta $6^{\circ}$ básico.

- Currículum más moderno y flexible: nuevos objetivos de aprendizaje, reconocimiento de modalidades especiales y modificación de los ciclos educativos (duración de 6 años para niveles de básica y media).

Así mismo, la ley establece la creación de la Agencia de Calidad y la Superintendencia de Educación, la reformulación del Consejo Superior de Educación en el Consejo Nacional de Educación y la reestructuración del Ministerio de Educación. (MINEDUC, 2010: 13-16)

\section{El segundo Gobierno de Michelle Bachelet y la Reforma Educacional de 2014}

El segundo gobierno de Michelle Bachelet se ha propuesto terminar con las lógicas de mercado que regulan el sistema educativo escolar -y también el de Educación Superior-, y al mismo tiempo lograr configurar un sistema más inclusivo y de calidad (Programa de gobierno de Michelle Bachelet $\left.{ }^{11}\right)$. Durante el año 2014 se dictó la Ley de Inclusión (firmada y publicada 29 de mayo del 2015), la cual pone fin al lucro (los sostenedores de los establecimientos educacionales particulares subvencionados deben conformarse como entidades sin fines de lucro), a la selección (tanto académica como por filiación al proyecto educativo) y al financiamiento compartido (los establecimientos no podrán cobrar un copago a las familias).

Si bien el proyecto coarta espacios de regulación y estructuración del sistema educativo bajo lógicas mercantiles, este no es claro en relación a la importancia y significancia de la educación pública. Si bien la ley pone en igualdad de condiciones a las escuelas públicas y privadas en el marco de la elección de los padres $\mathrm{y}$ acceso de sus hijos a estas, esta no cambia al sistema de financiamiento de las escuelas y tampoco cambia el capital simbólico que poseen ambos tipos de establecimiento. Teniendo en considera-

\footnotetext{
${ }^{11}$ Se puede acceder al programa de Gobierno en el sitio: http://michellebachelet.cl/programa/
} 
ción los perjuicios que han traído para la imagen de las escuelas públicas las movilizaciones estudiantiles, y la creencia de que el pago por la educación garantiza mayor calidad, es muy probable que siga bajando la matrícula debido a que los padres y apoderados, con la ley de inclusión que hace más accesible a las familias a entrar a las escuelas particulares subvencionadas, tenderán a buscar estabilidad que ofrecen las escuelas privadas subvencionadas.

Ahora bien, tal como hemos ido describiendo, el modelo de financiamiento y de administración de la educación en Chile no ha cambiado, por lo que las escuelas seguirán siendo financiadas bajo la misma fórmula del voucher por alumno; si a lo anterior se suma que los padres y apoderados tienden a escoger la educación privada (producto de la diferenciación y distinción social, y la creencia de que se paga por mejor educación), las desigualdades entre las escuelas seguirán existiendo, dado que los docentes se seguirán distribuyendo según el mercado (sueldo que cada sostenedor ofrezca), y dado el capital simbólico con que cuentan las escuelas privadas (ya sean subvencionadas o pagadas), es probable que los docentes se sigan distribuyendo de manera desigual.

\section{CONCLUSIONES}

A lo largo de este artículo hemos dado cuenta del desarrollo del sistema educativo y de los diversos problemas por los que actualmente se ve afectada la educación pública (la que se dicta en establecimientos administrados por el Estado) desde la dictadura hasta el gobierno de Sebastián Piñera. El deterioro de la educación pública ha de entenderse como multicausal y sistémico, dado que va desde la lógica del financiamiento del sistema educativo, hasta factores como la estabilidad laboral docente, el liderazgo directivo, y la estructuración del sistema educativo.

Acerca del desarrollo del sistema educativo y la educación pública en particular, podemos señalar que esta última, hasta antes de las reformas llevadas a cabo durante la dictadura militar, gozaba de una alta valoración e importancia, por lo que contaba con una serie de privilegios, dentro de los cuales se encontraba una subvención mayor que las que poseían las escuelas privadas. Al mismo tiempo, sus liceos eran altamente valorados socialmente 
y era la élite (política, social, política y económica) la que se educaba en sus aulas.

La reforma de la dictadura no solo puso en las mismas condiciones a las escuelas privadas y a las públicas en términos de subvención (financiamiento), sino que las puso derechamente a competir en condiciones desiguales, al posibilitar que las escuelas privadas subvencionadas seleccionaran y cobraran un copago a las familias, lo que ha generado que se lleve a cabo un proceso de descreme de estudiantes, quedando los más pobres y vulnerables en las escuelas públicas, y segregando aún más al sistema educativo. Al mismo tiempo, la selección de docentes y de directores se rige por criterios de mercado, a diferencia de como se hace en las públicas, que se encuentran bajo el marco del Estatuto Docente. Por ende, el sistema educativo chileno, tal como se encuentra organizado, no solo promueve y genera desigualdad educativa y social, sino que también promueve la distinción social de clase (Bourdieu, 2009).

En relación con las políticas educativas diseñadas desde la vuelta a la democracia, estas han sido fundamentalmente políticas de "focalización", tomando al estudiante o a las escuelas, pero sin discriminar si son públicas o privadas. Al mismo tiempo, no se ha diseñado una política educativa que apunte hacia lo público como prioritario o como beneficiario primordial; esto nos lleva a la hipótesis de que posicionar a lo público no ha sido prioritario para los gobiernos desde 1990 hasta la fecha. Esto no representa una problemática en particular si, como país, no existe una necesidad de diferenciar a la educación pública de la privada, producto de una histórica valoración de la segunda. Ahora bien, para tomar esa decisión, no basta solo con tener en cuenta el desarrollo y los procesos educativos que ha vivido el país, sino que también es necesario plantear la discusión del lugar que, como sociedad, queremos tanto para la educación pública como para la privada.

Si el país requiere verdaderamente que la educación pública vuelva a ser la que albergue a las grandes masas de ciudadanos (y de todos los sectores socioeconómicos) y sea el punto neurálgico de la cohesión social y meritocracia del sistema chileno, se necesita disponer ciertas desigualdades positivas hacia esta, tal como existía antes de la reforma a la dictadura, es decir, mayores 
recursos que incentiven no solo a los padres a poner a sus hijos en la educación pública, sino a trabajar ahí a los mejores docentes y directivos. Ahora, dado que también siempre ha existido una gran valoración hacia la educación privada en el desarrollo tanto subjetivo como objetivo del sistema educacional chileno en las últimas tres décadas, es razonable pensar que la ciudadanía chilena prefiera un sistema mixto, muy similar a lo que ocurre en países como Bélgica, Holanda, Suecia.

\section{REFERENCIAS BIBLIOGRÁFICAS}

Araya, Margarita, Pablo Barrientos, Tomás Ilabaca y Ambar Nuñez. Por el fin a la selección: el inicio de una educación inclusiva. Asuntos Públicos. Revisión 19-01-2016, 2015. Disponible en http://www.asuntospublicos.cl/2015/06/por-el-fin-a-laseleccion-inicio-de-una-educacion-inclusiva/

Bellei, Cristián. "El estudio de la segregación económica y académica de la educación chilena", en Estudios pedagógicos XXXIX, núm.1, Santiago de Chile, 2013, pp. 325-345.

Bellei, Cristián y Carolina Trivelli. Apoyo público a escuelas privadas. Casos nacionales y lecciones para Chile, Documento de Trabajo núm. 12, CIAE, Santiago de Chile, 2014, pp. 1-38.

Bellei, Cristián, Juan Pablo Valenzuela, Xavier Vanni y Dante Contreras. Lo aprendi en la escuela. ¿Cómo se logran procesos de mejoramiento escolar?, Santiago, LOM ediciones 2014.

Bertoglia, Raczynski y Valderrama, "Treinta años de política educativa descentralizada con efectos tardíos en calidad y equidad de la educación. ¿Ausencia de enfoque territorial?”, en Informe Latinoamericano Pobreza y Desigualdad, Santiago, Centro Latinoamericano para el Desarrollo Rural, 2011.

Beyer, Harald. ¿Qué hacer con la educación pública? Documento de Estudios públicos, núm. 114, Santiago, 2009, pp. 1-37.

Bourdieu, Pierre. Razones prácticas. Sobre la teoría de la acción, Barcelona, Anagrama, 2007.

Bourdieu, Pierre y Jean-Claude Passeron. Los herederos: los estudiantes y la cultura, Buenos Aires, Argentina, Siglo XXI, 2009.

Carrasco, Alejandro, Dante Contreras, Gregory Elacqua, Carolina Flores, Alejandra Mizala, Humberto Santos, Florencia Torche, Juan Valenzuela. "Hacia un sistema escolar más inclusivo: Cómo reducir la segregación escolar en Chile”, 
Informe de Politicas Públicas núm. 3, Santiago, Chile, Espacio Público, 2014, pp. 3-31.

Centro de Estudios Públicos. Resultados de Encuesta nacional de opinión pública. Julio, 2014. Disponible en http://www. cepchile.cl/1_5640/doc/estudio_nacional_de_opinion_ publica_julio_2014.html\#.VIDIZNKUe8. Fecha de acceso, 19 de enero de 2014.

Chubb J. E. y T. M. Moe. "Politics, markets, and the organization of schools", en American Political Science Review, vol. 84, núm. 04, 1998, pp. 1065-1087.

Corvalán, Javier. "Financiamiento compartido en la educación subvencionada chilena. Apuntes a partir de los resultados de una investigación", en Revista Persona y Sociedad, Chile, Universidad Alberto Hurtado, 2003, pp. 213-229.

Corvalán, Javier. "La narrativa educacional chilena y su proceso de transformación reciente: un análisis sociológico-histórico", en Revista Folios, Segunda época, primer Semestre, núm. 37, Santiago, 2013, pp 63-81.

Cox, Cristián. Politicas educacionales de Chile en las últimas dos décadas del siglo XX. Borrador, 2001. Disponible en http://cippec.org/mapeal/wp-content/uploads/2014/05/ Las-pol\%C3\%ADticas-educacionales-de-chile-en-las\%C3\%BAltimas-dos-d\%C3\%A9cadas-del-siglo-XX.pdf. Fecha de acceso, 19 de enero de 2016.

Cox, Cristián. "Las políticas educacionales de Chile en las últimas dos décadas del siglo XX”, en C. Cox. (Ed.), Políticas Educacionales en el cambio de siglo, Santiago, Chile, Editorial Universitaria, 2003, pp. 19-114

Cox, Cristián. Presentación ante la honorable cámara de diputados sobre formación inicial docente. Informe presentado a Comisión de Educación, Santiago, CEPPE, 2011. Disponible en http://www.ceppe.cl/images/stories/recursos/ publicaciones/cox/06-09-2011-Informe-Comision-Educacion.pdf. Fecha de acceso, 19 de enero de 2016.

Cox, Cristián y C. Jara. Datos básicos para la discusión de políticas en educación (1970-1988), Santiago, Centro de Investigación y Desarrollo de la Educación, CIDE, 1989.

Cox, Cristián, L. Ditzel, C. Henríquez, I. Irarrazabal, J. Jara, R. Medina, D. Raczynski, J. Sepúlveda y C. Tello. “¿Qué hacer con la educación municipal? Recomendaciones y 
desafíos para un nuevo sistema”, Santiago, Documento CEPPE y Centro de políticas Públicas UC, 2011, pp. 1-18.

Duncan, O. y B. Duncan. "A Methodological Analysis of segregation indexes", en American sociological review, vol. 20, núm. 2, 1995, pp. 210-217.

Egaña, Loreto. La educación primaria popular en el siglo XIX en Chile: una práctica de politica estatal, Santiago de Chile, Lom ediciones, 2000.

Fontaine, Loreto y Bárbara Eyzaguirre. "Una estructura que presione a las escuelas a hacerlo bien", en Beyer, H. y R. Vergara (Eds.), Qué hacer ahora. Propuestas para el desarrollo, Libro Digital del Centro de Estudios Públicos, 2001, pp. 66111. Disponible en http://www.cepchile.cl/dms/lang_1/ cat_770_pag_1.html. Fecha de acceso, 19 de enero de 2016.

Hsieh, Chang-Tai. y Miguel Urquiola. "The effects of generalized school choice on achievement and stratification: evidence from Chile's voucher program", en Journal of Public Economics, vol. 90, núms. 8-9, Amsterdam, Elsevier, 2006, pp. 1477-1503.

Jofré, Gerardo. "El sistema de subvenciones en educación: la experiencia chilena”, en Revista Estudios Públicos, núm. 32, Santiago de Chile, 1988, pp. 194-237.

Kremerman, Marco. Desalojo de la universidad pública, Santiago de Chile, s/f. Disponible en http://www.opech.cl/inv/investigaciones/Kremerman_Desalojo_Universidad_Publica.pdf. Fecha de acceso, 19 de enero de 2016.

Mauger, Gérard. "La teoría de la reproducción frente al reto de la democratización escolar", en Carvacho, C. et al. La escolarización de los adolescentes: desafios culturales, pedagógicos y de politica educativa, Buenos Aires, IIPE-UNESCO, 2012, pp. 19-53.

Mayol, Alberto y Carla Azócar. "Politización del malestar, movilización social y transformación ideológica: el caso 'Chile 2011 '”, en Polis, Revista de la Universidad Bolivariana, vol. 10, núm. 30, 2011, pp. 163-184.

MINeduC. Calidad para Todos. Cuenta Pública Ministerio de Educación 2006-2010, Santiago, Chile, 2010.

MINEDUC. Los aprendizajes en la escuela: ampliando la mirada de calidad. Resultados, 2013. Apuntes sobre la calidad, Disponible en http://www.agenciaeducacion.cl/. Fecha de acceso, 29 enero de 2016. 
MINEDUC. Los aprendizajes en la escuela: ampliando la mirada de calidad. Resultados, 2013. Apuntes sobre la calidad, 2014. Disponible en http://www.agenciaeducacion.cl/. Fecha de acceso, 29 enero de 2016.

MINEDUC. "Clima de convivencia escolar según los estudiantes de II medio", en Apuntes sobre la calidad de la educación, núm. 10, 2013. Disponible en https://s3.amazonaws.com/archivos. agenciaeducacion.cl/documentos-web/Papers/2013_10_Clima_de_convivencia_escolar_segun_los_estudiantes_de_II_ medio.pdf. Fecha de acceso, 19 de enero de 2016.

Picazo Verdejo, María Inés. Las políticas escolares de la Concertación durante la transición democrática, Santiago de Chile, Universidad Diego Portales, 2013.

Román, Marcela. Un sistema educativo de dos cabezas. ¿Quién responde por las escuelas públicas en Chile?, Buenos Aires, Aique, 2007.

Román, M. y A. Carrasco. "Los niveles intermedios del sistema escolar chileno: posibilidades y limitaciones para la equidad", en REICE. Revista Electrónica Iberoamericana sobre Calidad, Eficacia y Cambio en Educación, vol. 5, núm. 1, 2007.

Serrano, Sol. Universidad y nación. Chile en el siglo XIX, Santiago, Editorial Universitaria, 1993.

Serrano, Sol, Macarena Ponce de León, Francisca Rengifo. "Historia de la educación en Chile (1810-2010)". Tomo 1. Aprender a leer y escribir (1810-1880), Santiago de Chile, Taurus, 2012.

OCDE. Revisión de politicas nacionales de educación: La educación superior en Chile, Santiago de Chile, Ministerio de Educación, 2009.

Ossa, Juan Luis. "El Estado y los particulares en la educación chilena, 1888-1920", en Estudios públicos, núm. 106, Chile, Centro de Estudios Públicos (CEP), 2007, pp. 23-96.

Raczynsky, Dagmar, Luz María Pérez, Cristián Bellei, Gonzalo Muñoz. ¿Quién dijo que no se puede? Escuelas efectivas en sectores de pobreza, Santiago de Chile, Encargado por UNICEF, 2004.

Weinstein, José y Gonzalo Muñoz. ¿Qué sabemos de los directores de escuela?, Santiago, Chile, Ediciones CEPPE-UC, 2012.

Waissbluth, Mario y Ximena Pizarro. "Diagnóstico y propuesta para el sistema de selección de directivos escolares", en Documento de trabajo, serie "Sistemas públicos", Chile, Centro de Sistemas Públicos de la Facultad de Ingeniería Industrial, Universidad de Chile, núm. 10, 2014, pp. 1-19. 